\section{Evaluation of Aluminum Resistance among Zoysia Willd. Accessions from China}

\author{
Chun-qiong Huang', Guo-dao Liu, and Chang-jun Bai \\ Tropical Crops Genetic Resources Institute, Chinese Academy of Tropical \\ Agricultural Sciences/Key Laboratory of Crop Gene Resources and Germplasm \\ Enhancement in Southern China, Ministry of Agriculture, Danzhou, Hainan, \\ China
}

Additional index words. zoysiagrass, acidity and aluminum stress, variation analysis, clustering analysis, small-scale liquid culture

\begin{abstract}
Aluminum ion $\left(\mathrm{Al}^{3+}\right)$ toxicity is a major factor limiting plant production on acid soils. Species of zoysiagrass (Zoysia Willd.) are grown for lawn, turf, and soil conservation, especially in temperate zones. Herein, 46 zoysiagrass accessions obtained from eight provinces in China were evaluated for $\mathrm{Al}$ resistance using small-scale liquid culture. Each accession was grown in triplicate in nutrient solutions with $1500 \mu \mathrm{M} \mathrm{AlCl} \mathrm{Al}_{3} \cdot 6 \mathrm{H}_{2} \mathrm{O}$ (experimental) or without exposure to $\mathrm{Al}$ (control). The mean dry weights of the roots, shoots, and total bodies of the accessions relative to those of the nontreated controls were calculated after 60 days, and showed considerable diversity. Overall, the $\mathrm{CV}$ for the shoot, root, and total weights of the Al-treated accessions relative to the nontreated controls were $45.78 \%, 56.67 \%$, and $42.84 \%$, respectively. A cluster analysis based on Al resistance and subordinate function values revealed that 12 of the 46 zoysiagrass accessions (26.09\%) were resistant to $\mathrm{Al}, 9(19.57 \%)$ were moderately resistant, and $25(54.35 \%)$ were sensitive to Al stress. These 46 zoysiagrass accessions from China have great potential for horticultural breeding and development, and for research into mechanisms that underlie Al resistance.
\end{abstract}

Soil acidification is normally a slow process, and acidic or acid soils are natural in humid tropical, subtropical, and temperate regions. However, the acidification of soil may be aggravated unnaturally by acid rain due to industrial emissions, or applications of acid fertilizers, and it is estimated that worldwide $40 \%$ of cultivated land is now acidic. In China, areas with acid soil are widely distributed across 14 provinces, primarily in the south. The total area affected is about 2.03 million square hectometer, comprising $21 \%$ of domestic farmland (Ying et al., 2006). Acid soils made toxic by heavy metals such as $\mathrm{Al}$ inhibit the growth of pasture and crops. Although $\mathrm{Al}$ is the third most abundant element in the earth's crust (after oxygen and silicon), its form in the soil is dependent on soil potential of hydrogen $(\mathrm{pH})$. As soil becomes acidic, particularly when the $\mathrm{pH}$ is below 5.5, $\mathrm{Al}$ (mainly as free $\mathrm{Al}$ ions, or $\mathrm{Al}^{3+}$ ) and some micronutrients become more soluble and toxic to plants. Concurrently, most of the nutrients required by plants are less available

Received for publication 1 July 2016. Accepted for publication 8 Dec. 2016.

This work was supported by the National Nonprofit Institute Research Grant of CATAS-TCGRI (no. 1630032014028).

We acknowledge the editors and the anonymous reviewers for their valuable comments to improve this manuscript.

${ }^{1}$ Corresponding author. E-mail: huangchunqiong44@ 163.com
(Kochian et al., 2005). Thus, in acid soils Al toxicity is a primary inhibitor of plant growth (Armiger et al., 1968), plants exhibit signs of nutrient deficiencies, and they are also less able to withstand stress (Marschner, 1991).

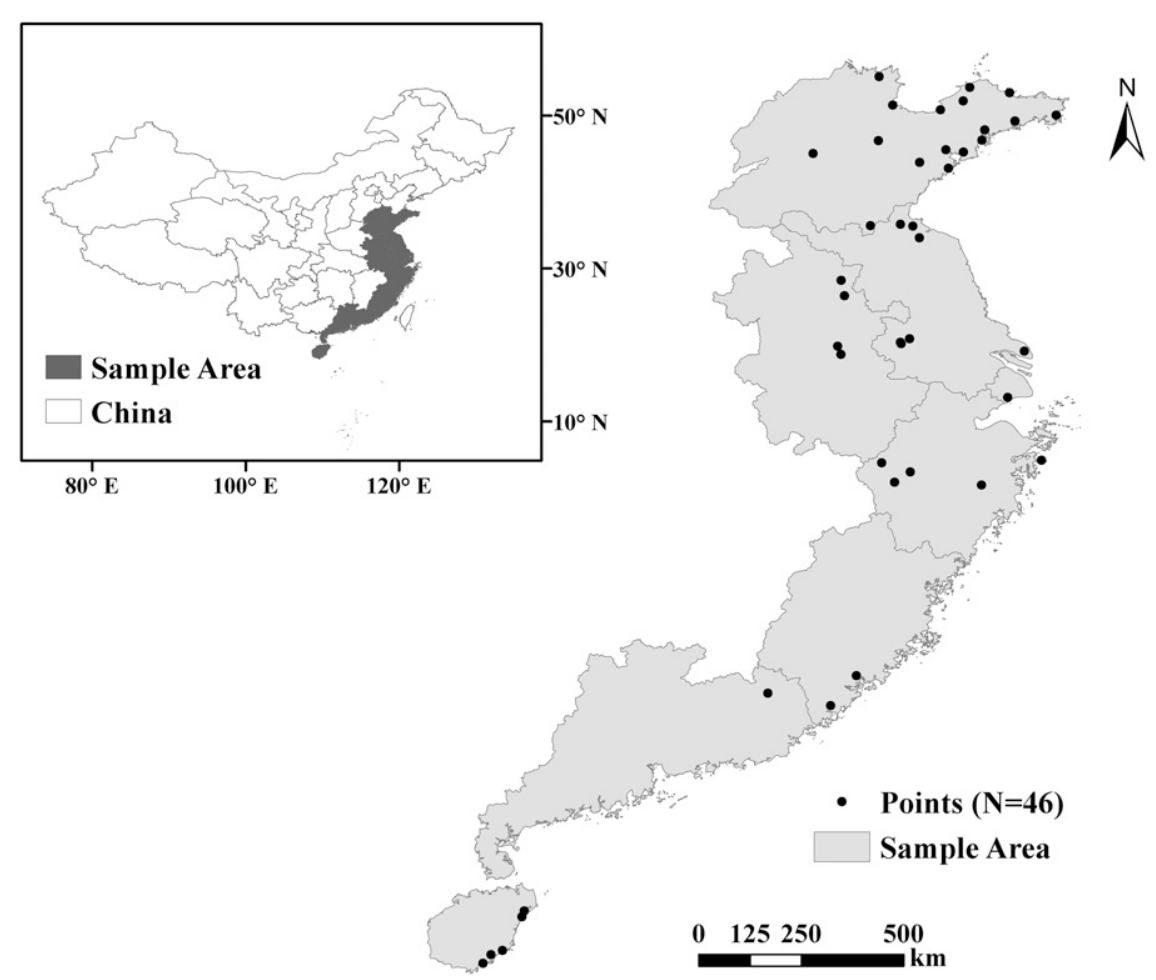

Fig. 1. A map showing the collection sites for the 46 Zoysia Willd. accessions from China.
In agricultural practice, the two main approaches to improve plant growth in acid soils have been soil conditioning and breeding Al-resistant plant lines. Regarding soil conditioning, chemicals such as lime and other ameliorants are applied to neutralize the soil (i.e., increase the $\mathrm{pH}$ ) and therefore decrease the solubility of $\mathrm{Al}^{3+}$. However, lime affects only the soil surface and longterm application changes the soil's structure and other features. Soil ameliorants are effective only for the short term, are expensive, and their improper application decreases the solubility of other micronutrients such as zinc and iron and leads to over-decomposition of soil organics, to the detriment of the ecological environment. In terms of environmental conservation and protection, using plant germplasm resources for bioremediation of the soil (i.e., phytoremediation) is preferable to adding further chemicals to raise the soil's $\mathrm{pH}$. The primary goal of phytoremediation on agricultural land is to return the soil's ecology to one that can support crop production. Remedial plant species should have Al resistance and high biomass. Zoysiagrass (Zoysia Willd., family Poaceae) is a perennial turfgrass that is mainly grown in temperate and humid tropical and subtropical regions (Guo et al., 2012). Its resistances to drought, cold, and salinity have made it popular all over the world for lawn and turf, and for soil conservation (Guo et al., 2012, 2014). There are 11 identified Zoysia species, five of which are distributed in China (Z. japonica, Z. matrella, Z. tenuifolia, $Z$. sinica, and Z. macrostachya) (Guo et al., 2014). In tropical southern China, soil acidification is an acute problem in pasture production and lawn conservation (Murray and Foy, 1978). The selection and breeding of 
Al-resistant zoysiagrass accessions could improve pasture production and lawn quality in these areas of acid soils.

Although studies on Al resistance in plants have included crops such as Zea mays (Garzón et al., 2011; Keltjens, 1995; Maron et al., 2013), Sorghum bicolor (Sivaguru et al., 2013), Oryza sativa (Chen et al., 2012; Jan, 1991; Tsutsui et al., 2012), and Triticum aestivum (Delhaize et al., 1993; GarciaOliveira et al., 2013; Raman et al., 2010; Zhou et al., 2013), little progress has been made in grass species (Arroyave et al., 2013; Baldwin et al., 2005; Campbell et al., 1994; Duncan and Shuman, 1993; Ezaki et al., 2013; Gould et al., 2014; Liu, 2005; Yan et al., 2009). It has been suggested that differences in Al resistance among grass species or varieties is linked to genetic variations. Thus, the characterization of $\mathrm{Al}$ resistance in zoysiagrass and screening for Al-resistant accessions may enable grass breeders to improve and remediate acid soils. In this study, 46 zoysiagrass accessions from eight provinces in China were evaluated for Al resistance using small-scale liquid cultivation. The information we provide herein is fundamental to the selection of Al-resistant lines, as well as investigations into the resistance mechanisms of zoysiagrass.

\section{Materials and Methods}

\section{Plant material}

Forty-six native Zoysia Willd. accessions, which contained $1 Z$. sinica Hance., $7 Z$. matrella (Linn.) Merr., and 38 Z. japonica Steud., were collected from eight provinces in China from 2004 to 2008, ranging from tropical Hainan Island to the temperate climatic region around Shandong, between $18^{\circ}$ $\mathrm{N}$ and $37^{\circ} \mathrm{N}$ latitudes and between $109^{\circ} \mathrm{E}$ and $122^{\circ} \mathrm{E}$ longitudes (Fig. 1; Table 1). Each accession was originally collected from grassland, roadside, or seaside, and was cultured in one $20-\mathrm{cm}$ diameter pots in the greenhouse under uniform conditions at the Tropical Crops Genetic Resources Institute, Chinese Academy of Tropical Agricultural Sciences, Danzhou, Hainan Province, China (1998" N, 110³2" E; elevation $176 \mathrm{~m}$ ).

\section{Plant growth}

To ensure enough young seedlings for the experiments and a uniformity control, stolons of only one bud from each of the 46 zoysiagrass accessions were cut and cultivated in bags. In early July 2013, stolons at identical developmental stages were selected and cut into similar fragments (one node) and planted in $250-\mathrm{mL}$ plastic cups (diameter $6.5 \mathrm{~cm}$, height $9.5 \mathrm{~cm}$, with six drilled holes at the bottom) filled with silica sand. Each accession was planted in six cups (three cups for treatments in one container, three cups for control in another container), and each cup held three sprig fragments.

Plants were grown by small-scale liquid cultivation. The plastic cups $(200 \mathrm{~mL}, 6.5 \mathrm{~cm}$ in diameter, $7.5 \mathrm{~cm}$ in height) hung in foam plate each with three cups of a single accession, floating in a big container $(45.0 \mathrm{~cm}$ in length, $32.0 \mathrm{~cm}$ in width, and $16.0 \mathrm{~cm}$ in height) filled with $10 \mathrm{~L}$ half-strength Hoagland nutrient solution that was aerated continuously by an aerating pump and changed every $3 \mathrm{~d}$ (Yan et al., 2009). All accessions were cultured for 2 weeks under greenhouse conditions before the experiments began. The greenhouse was maintained at $32{ }^{\circ} \mathrm{C}$ to $38{ }^{\circ} \mathrm{C}$ during the day, $24{ }^{\circ} \mathrm{C}$ to $30.5{ }^{\circ} \mathrm{C}$ at night, with $90 \%$ natural sunlight and a relative humidity range of $40 \%$ to $75 \%$ during the study.

\section{Al treatment}

After 2 weeks, plants were treated with $\mathrm{Al}$ $\left(\mathrm{AlCl}_{3} \cdot 6 \mathrm{H}_{2} \mathrm{O}\right)$ at concentrations of 0 (control) or $1500 \mu \mathrm{M}$ (treatment) (Liu, 2005; Yan et al., 2009). The treatment period lasted $60 \mathrm{~d}$. The $\mathrm{pH}$ of the nutrient solutions was adjusted to $4.0 \pm 0.2$ using $\mathrm{HCl}$ or $\mathrm{NaOH}$, as appropriate, measured with a portable $\mathrm{pH}$ meter. All nutrient solutions were aerated continuously with an aerating pump and solutions were changed every $3 \mathrm{~d}$. The volume of the solution was maintained by replenishing water on a daily basis. Figure 2 showed the experimental design.

\section{Data acquisition and statistical analyses}

Measurement of root and shoot dry weight. At the end of the treatment period $(60 \mathrm{~d})$, the shoots and roots were separated and rinsed three times with deionized water. The plant materials were kept at $105^{\circ} \mathrm{C}$ for $15 \mathrm{~min}$ and then dried at $75^{\circ} \mathrm{C}$ for $48 \mathrm{~h}$. The dried material was weighed on a scale. For each individual growth cup, the relative dry weights of plants (shoot, root, or total) in the Al-treated groups were calculated as a percentage of the average dry weight of the corresponding nontreated control plant parts. Specifically, the relative shoot weight (RSW),

Table 1. Geographical origins of 46 zoysiagrass accessions investigated in the present study.

\begin{tabular}{|c|c|c|c|c|c|}
\hline Accession & Species & Origin & Accessions & Species & Origin \\
\hline$\overline{\mathrm{Z} 02}$ & Z. sinica & Nanjing, Jiangsu & Z29 & Z. japonica & Lianyungang, Jiangsu \\
\hline $\mathrm{Z} 03$ & Z. japonica & Lianyungang, Jiangsu & $\mathrm{Z} 30$ & Z. japonica & Qingdao, Shandong \\
\hline Z04 & Z. japonica & Qingdao, Shandong & Z31 & Z. japonica & Wuhe, Anhui \\
\hline $\mathrm{Z} 05$ & Z. japonica & Rongcheng, Shandong & $\mathrm{Z} 32$ & Z. japonica & Jinshan, Shanghai \\
\hline Z06 & Z. japonica & Xianju, Zhejiang & Z33 & Z. japonica & Kaihua, Zhejiang \\
\hline $\mathrm{Z} 07$ & Z. japonica & Lianyungang, Jiangsu & Z34 & Z. japonica & Qingdao, Shandong \\
\hline Z08 & Z. japonica & Weifang, Shandong & $\mathrm{Z} 35$ & Z. matrella & Tong'an, Fujian \\
\hline Z09 & Z. japonica & Longyou, Zhejiang & Z36 & Z. matrella & Zhangpu, Fujian \\
\hline $\mathrm{Z} 10$ & Z. japonica & Yantai, Shandong & Z37 & Z. japonica & Feidong, Anhui \\
\hline $\mathrm{Z} 13$ & Z. japonica & Dongying, Shandong & Z38 & Z. japonica & Weihai, Shandong \\
\hline $\mathrm{Z} 14$ & Z. japonica & Tai'an, Shandong & Z39 & Z. japonica & Nantong, Jiangsu \\
\hline $\mathrm{Z} 15$ & Z. japonica & Yantai, Shandong & $\mathrm{Z} 40$ & Z. japonica & Weifang, Shandong \\
\hline Z16 & Z. japonica & Bengbu, Anhui & Z41 & Z. japonica & Nanjing, Jiangsu \\
\hline Z18 & Z. japonica & Quzhou, Zhejiang & $\mathrm{Z} 42$ & Z. japonica & Qingdao, Shandong \\
\hline Z19 & Z. japonica & Linyi, Shandong & Z43 & Z. japonica & Rongcheng, Shandong \\
\hline $\mathrm{Z} 21$ & Z. japonica & Xiangshan, Zhejiang & $\mathrm{Z} 44$ & Z. japonica & Yantai, Shandong \\
\hline $\mathrm{Z} 22$ & Z. japonica & Kaihua, Zhejiang & $\mathrm{Z} 45$ & Z. japonica & Qingdao, Shandong \\
\hline $\mathrm{Z} 23$ & Z. japonica & Nanjing, Jiangsu & Z46 & Z. matrella & Wenchang, Hainan \\
\hline Z24 & Z. japonica & Yantai, Shandong & Z47 & Z. matrella & Wenchang, Hainan \\
\hline $\mathrm{Z} 25$ & Z. japonica & Qingdao, Shandong & Z48 & Z. matrella & Lingshui, Hainan \\
\hline Z26 & Z. japonica & Nanjing, Jiangsu & Z49 & Z. matrella & Lingshui, Hainan \\
\hline $\mathrm{Z} 27$ & Z. japonica & Feidong, Anhui & $\mathrm{Z} 50$ & Z. matrella & Wanning, Hainan \\
\hline Z28 & Z. japonica & Yantai, Shandong & Z51 & Z. japonica & Meizhou, Guangdong \\
\hline
\end{tabular}

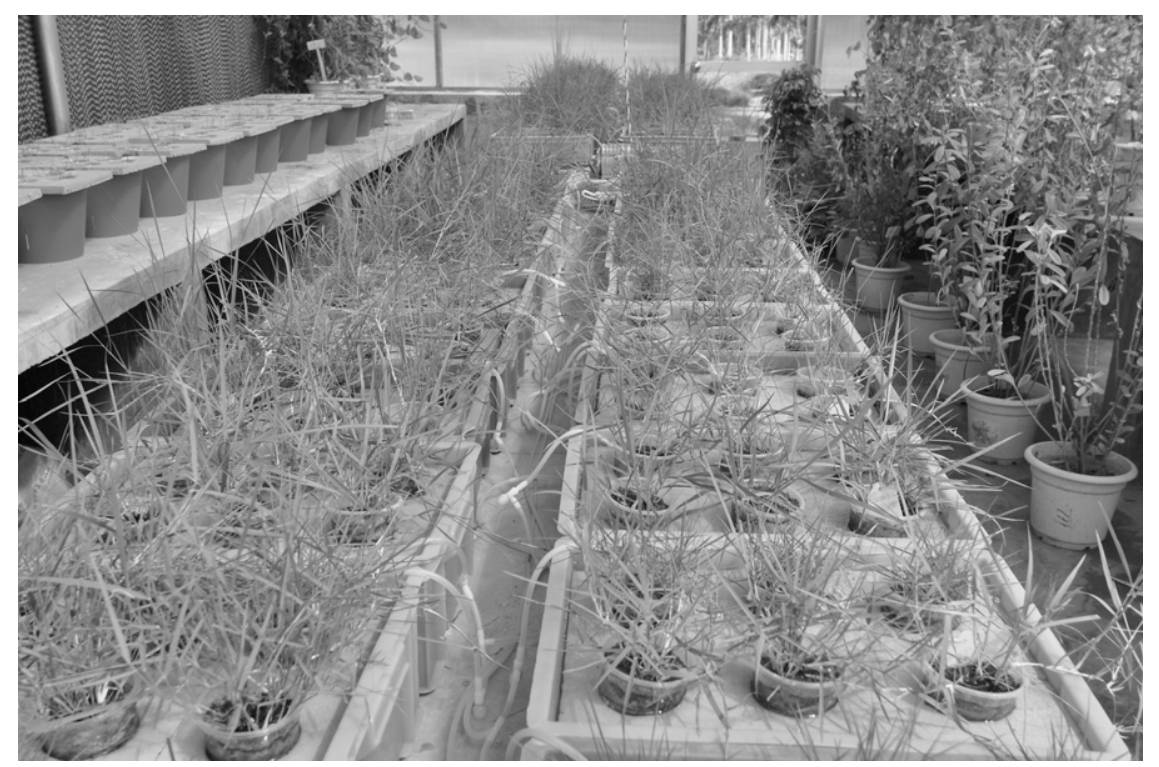

Fig. 2. A picture of greenhouse showing the experimental design. 
relative root weight (RRW), and relative total weight (RTW) were calculated.

Subordinate function value of $\mathrm{Al}$ resistance. The $\mathrm{Al}$ resistance of each zoysiagrass accession $i$ was ranked by the subordinate function value for $\mathrm{Al}$ resistance $(\mathrm{F}): \mathrm{F}_{i}=$ $\left(X_{i j}-X_{\min }\right) /\left(X_{\max }-X_{\min }\right)$, where $X_{i j}$ is the average value of feature $j$ of accession $i$, and $X_{\min }$ and $X_{\max }$ are the minimum and maximum values, respectively, of feature $j$ of accession $i$. The average $\mathrm{F}$ value of each accession $i$ was defined as the average $\mathrm{F}_{i}$ of all features (Wang et al., 2013). The data were compiled using Microsoft Excel and analyzed using the Statistical Analysis System (SAS) Software. Values of the relative growth parameters (RSW, RRW, and RTW) were submitted to analysis of variance procedures and parameters. Means were separated using Duncan's multiple range test ( $\alpha=0.05)$ using the SAS program. Cluster analysis based on the relative growth parameters (RSW, RRW, and RTW) using the Euclidean distance was performed according to hierarchical clustering analysis of the SAS program.

\section{Results}

Effect of Al treatment on vegetative growth in 46 zoysiagrass accessions. After the 60-d experimental period, comparisons were conducted of the root, shoot, or total weights of the treated 46 zoysiagrass accessions, relative to the weights of the corresponding nontreated controls (RRW, RSW, and RTW, respectively; Table 2). Relative root weight varied the most, from $5.80 \%$ to $470.87 \%$, with a $\mathrm{CV}$ of $56.67 \%$. This indicates that great diversity exists among the accessions with regard to $\mathrm{Al}$ resistance. Relative shoot weight ranged from $28.87 \%$ to $222.87 \%$, and RTW from $31.88 \%$ to $214.09 \%(\mathrm{CVs}=45.78 \%$ and $42.84 \%$, respectively).

Cluster analysis. The 46 accessions were classified into four groups (I-IV) after a hierarchical clustering analysis of the RRW, RSW, and RTW data (Euclidean distance $=0.85$; Fig. 3). Group I comprised two accessions (Z41 and Z23) consisting of $4.35 \%$ of all evaluated materials. The mean $F$ value for Al resistance was $0.6778(0.5543-0.8012)$, indicating that the $\mathrm{Al}$ resistance of Group I was above average. Group II included six

Table 2. Effect of aluminum treatment on vegetative growth and $F$ value in 46 Zoysia Willd. accessions.

\begin{tabular}{|c|c|c|c|c|c|}
\hline Accession & Relative shoot wt (\%) & Relative root wt $(\%)$ & Relative total wt (\%) & Subordinate function value & Resistance level \\
\hline$\overline{\mathrm{Z} 02}$ & 79.59 bcde & 154.63 bcdefgh & 86.03 bcdef & 0.1656 & 5 \\
\hline $\mathrm{Z} 03$ & $52.03 \mathrm{de}$ & 237.14 abcdefgh & 63.64 def & 0.4933 & 4 \\
\hline Z04 & $57.19 \mathrm{de}$ & 135.00 cdefgh & $61.93 \mathrm{def}$ & 0.1666 & 5 \\
\hline Z05 & $45.34 \mathrm{e}$ & 137.44 cdefgh & 53.90 ef & 0.2841 & 5 \\
\hline Z06 & $67.11 \mathrm{de}$ & $78.23 \mathrm{efgh}$ & $67.46 \mathrm{cdef}$ & 0.4401 & 4 \\
\hline $\mathrm{Z} 07$ & 105.07 abcde & 117.89 cdefgh & 105.69 abcdef & 0.1296 & 5 \\
\hline Z08 & $69.09 \mathrm{de}$ & $359.36 \mathrm{abc}$ & 83.75 bcdef & 0.3127 & 5 \\
\hline Z09 & $65.83 \mathrm{de}$ & 83.32 efgh & 66.34 def & 0.6726 & 3 \\
\hline $\mathrm{Z} 10$ & 146.17 abcde & 286.18 abcdefg & 160.47 abcde & 0.7193 & 3 \\
\hline $\mathrm{Z} 13$ & 91.88 bcde & 110.20 cdefgh & 93.08 abcdef & 0.3572 & 4 \\
\hline Z14 & $71.07 \mathrm{de}$ & 168.63 bcdefgh & 78.77 bcdef & 0.1201 & 5 \\
\hline $\mathrm{Z} 15$ & $67.91 \mathrm{de}$ & $54.25 \mathrm{fgh}$ & 66.52 def & 0.1821 & 5 \\
\hline Z16 & 104.06 abcde & 115.00 cdefgh & 105.76 abcdef & 0.1962 & 5 \\
\hline Z18 & $59.82 \mathrm{de}$ & 79.22 efgh & $61.55 \mathrm{def}$ & 0.5040 & 3 \\
\hline Z19 & $52.34 \mathrm{de}$ & 152.94 bcdefgh & 60.39 def & 0.2016 & 5 \\
\hline $\mathrm{Z} 21$ & 136.92 abcde & 248.33 abcdefgh & 142.56 abcdef & 0.5479 & 3 \\
\hline $\mathrm{Z} 22$ & $65.99 \mathrm{de}$ & 175.46 bcdefgh & 74.71 bcdef & 0.2215 & 5 \\
\hline $\mathrm{Z} 23$ & $199.73 \mathrm{ab}$ & 185.42 bcdefgh & $197.07 \mathrm{ab}$ & 0.5543 & 3 \\
\hline $\mathrm{Z} 24$ & 77.19 bcde & 172.44 bcdefgh & 87.05 bcdef & 0.2573 & 5 \\
\hline $\mathrm{Z} 25$ & $196.96 \mathrm{abc}$ & 312.79 abcdef & $214.09 \mathrm{a}$ & 0.6917 & 3 \\
\hline Z26 & $146.11 \mathrm{abcde}$ & 214.93 bcdefgh & 152.92 abcdef & 0.7271 & 3 \\
\hline $\mathrm{Z} 27$ & 108.94 abcde & 104.61 cdefgh & 108.63 abcdef & 0.4068 & 4 \\
\hline $\mathrm{Z} 28$ & 100.82 bcde & 201.30 bcdefgh & 110.66 abcdef & 0.3136 & 5 \\
\hline Z29 & 74.92 cde & 106.07 cdefgh & 76.71 bcdef & 0.3112 & 5 \\
\hline $\mathrm{Z30}$ & 139.00 abcde & 144.44 bcdefgh & 138.21 abcdef & 0.9530 & 1 \\
\hline Z31 & 78.70 bcde & 226.23 abcdefgh & 90.72 abcdef & 0.4154 & 4 \\
\hline $\mathrm{Z} 32$ & 91.23 bcde & 98.74 defgh & 92.39 abcdef & 0.1997 & 5 \\
\hline $\mathrm{Z33}$ & $63.34 \mathrm{de}$ & 324.22 abcde & 77.32 bcdef & 0.2989 & 5 \\
\hline Z34 & $28.87 \mathrm{e}$ & 87.20 defgh & $31.88 \mathrm{f}$ & 0.0932 & 5 \\
\hline Z35 & 105.26 abcde & 157.25 bcdefgh & 110.25 abcdef & 0.2157 & 5 \\
\hline Z36 & 101.65 bcde & 167.68 bcdefgh & 106.36 abcdef & 0.5129 & 3 \\
\hline $\mathrm{Z} 37$ & 113.91 abcde & $394.93 \mathrm{ab}$ & 140.59 abcdef & 0.6206 & 3 \\
\hline Z38 & 90.52 bcde & 132.77 cdefgh & 93.95 abcdef & 0.1942 & 5 \\
\hline Z39 & $38.76 \mathrm{e}$ & 125.88 cdefgh & $44.93 \mathrm{ef}$ & 0.3650 & 4 \\
\hline $\mathrm{Z} 40$ & 90.76 bcde & 126.64 cdefgh & 92.16 abcdef & 0.2774 & 5 \\
\hline Z41 & $222.87 \mathrm{a}$ & 95.53 defgh & $194.66 \mathrm{abc}$ & 0.8012 & 2 \\
\hline Z42 & 88.98 bcde & 287.18 abcdefg & 105.29 abcdef & 0.4426 & 4 \\
\hline Z43 & $173.16 \mathrm{abcd}$ & $344.57 \mathrm{abcd}$ & 186.48 abcd & 0.9726 & 1 \\
\hline Z44 & 79.71 bcde & $65.16 \mathrm{fgh}$ & 74.00 bcdef & 0.0353 & 5 \\
\hline $\mathrm{Z} 45$ & 75.00 cde & 272.08 abcdefg & $87.58 \mathrm{bcdef}$ & 0.4108 & 4 \\
\hline Z46 & $46.30 \mathrm{e}$ & $34.08 \mathrm{gh}$ & 45.15 ef & 0.0713 & 5 \\
\hline $\mathrm{Z} 47$ & $71.53 \mathrm{de}$ & $470.87 \mathrm{a}$ & 95.27 abcdef & 0.3238 & 5 \\
\hline Z48 & 108.74 abcde & $5.80 \mathrm{~h}$ & 57.27 ef & 0.0016 & 5 \\
\hline Z49 & 114.61 abcde & $151.21 \mathrm{bcdefgh}$ & 117.79 abcdef & 0.1821 & 5 \\
\hline $\mathrm{Z} 50$ & 88.06 bcde & 182.38 bcdefgh & 94.05 abcdef & 0.3465 & 5 \\
\hline Z51 & $52.94 \mathrm{de}$ & 290.47 abcdefg & $64.58 \mathrm{def}$ & 0.4669 & 4 \\
\hline Maximum & 222.87 & 470.87 & 214.09 & 0.9726 & \\
\hline Minimum & 28.87 & 5.80 & 31.88 & 0.0016 & \\
\hline Mean & 93.61 & 177.74 & 98.26 & 0.3734 & \\
\hline $\mathrm{SE}$ & 42.85 & 100.73 & 42.09 & 0.2328 & \\
\hline CV $(\%)$ & 45.78 & 56.67 & 42.84 & 62.33 & \\
\hline$F$ value & $1.48^{\mathrm{NS}}$ & $1.91 * *$ & $1.38^{\mathrm{NS}}$ & & \\
\hline
\end{tabular}

Values within a column followed by the different letters are significantly different at 5\% level of probability based on Duncan's multiple range test.

Ns, *, ** Nonsignificant or significant at $P<0.05$ or 0.01 , respectively. 


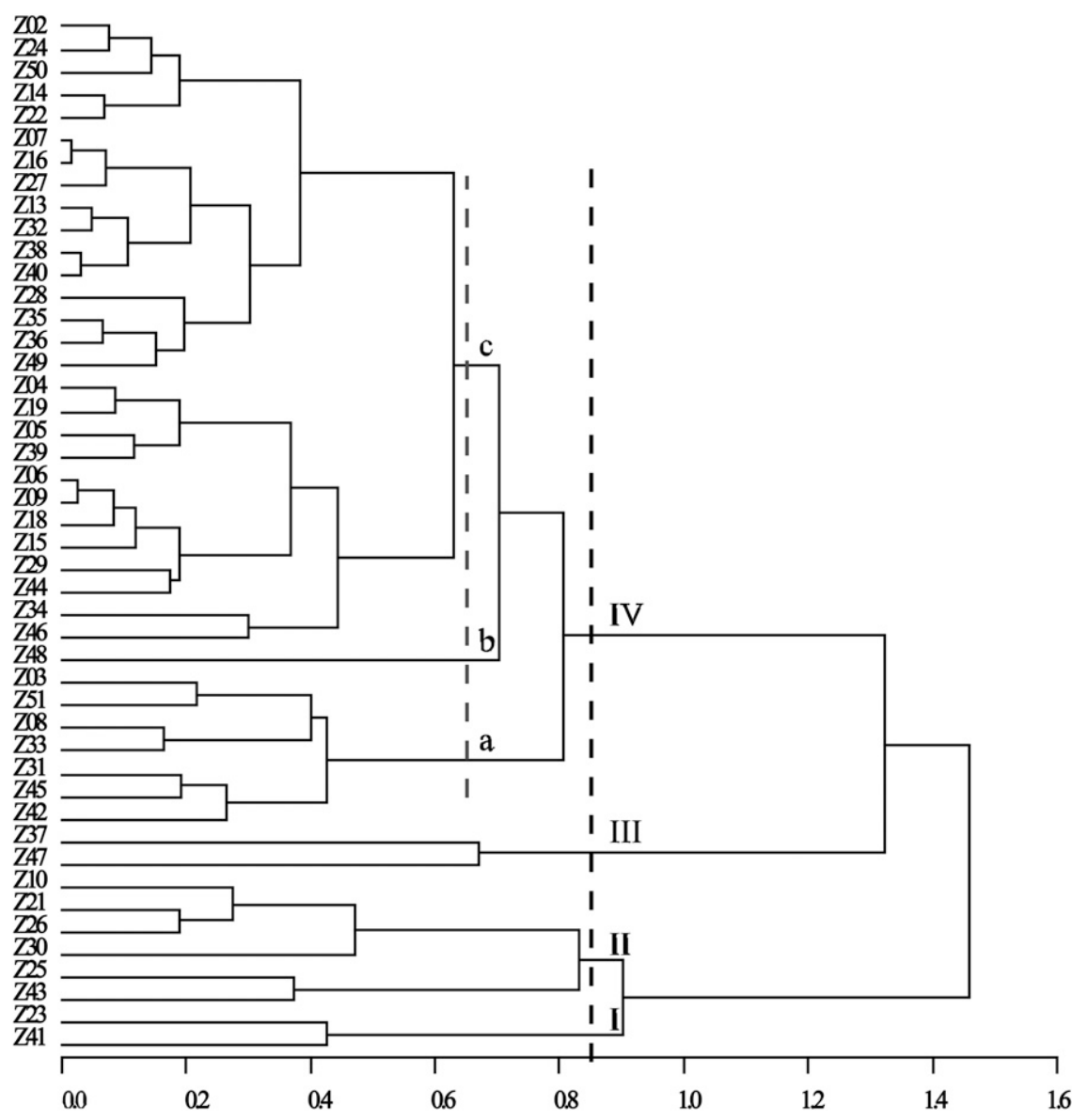

Fig. 3. Cluster dendrogram of the 46 Zoysia Willd. accessions from China, based on their aluminum resistance.

accessions (Z43, Z25, Z30, Z26, Z21, and Z10), comprising $13.04 \%$ of all the plant materials. The mean $F$ was 0.7689 (0.5479$0.9726)$ indicating high $\mathrm{Al}$ resistance. Accessions Z43 and Z30 $(F=0.9726$ and 0.9530 , respectively) were the most $\mathrm{Al}$ resistant.

Group III included two accessions (Z37 and Z47) comprising $4.35 \%$ of all evaluated materials. This group has moderate Al resistance $[F=0.4722(0.3238-0.6206)]$.

The 36 accessions in Group IV account for $78.26 \%$ of all accessions. These were further stratified into three subgroups (IVa, $\mathrm{IVb}$, and IVc), with a Euclidean distance of 0.70 . Subgroup IVa consists of seven accessions, with below-average $\mathrm{Al}$ resistance $[F=0.4058(0.2989-0.4933)]$. Subgroup IVb holds only one accession, and the $F$ value indicates sensitivity to $\mathrm{Al}(\mathrm{Z} 48 ; F=0.0016)$. Subgroup IVc includes 28 accessions, and resistance to $\mathrm{Al}$ is weak $[F=0.2651(0.0353$ 0.6726)].

Ranking on Al resistance in zoysiagrass accessions. Based on the results of the cluster analysis and the subordinate function values, the 46 accessions were ranked into five levels of $\mathrm{Al}$ resistance: level 1 very highly resistant $(F \geq 0.9)$; level 2 , highly resistant $(0.75 \leq$ $F<0.9)$; level 3, moderately resistant $(0.50 \leq$ $F<0.75)$; level 4 , neutral resistance $(0.35 \leq$ $F<0.50)$; and level 5 , sensitive to $\mathrm{Al}(F<$ 0.35 ). Among the evaluated 46 zoysiagrass accessions, $12(26.09 \%)$ accessions belong to
Although convenient and efficient, liquid culture also has disadvantages. Plants in the same container can be influenced by complex biochemical reactions. For example, organic acids, phosphoric acid, and colloids may be secreted by Al-resistant plants under treatment, or $\mathrm{pH}$ elevation can occur in the rhizosphere. To prevent such problems, small-scale liquid culture (in vitro culture) has been used for Al resistance screening. Aluminum toxicity in plants is caused by an interaction between $\mathrm{Al}^{3+}$ and the root tip, which inhibits root development. Therefore, reduced root growth is the most obvious sign of Al toxicity and is used when accessing Al resistance. In Eremochloa ophiuroides, changes in the growth of aerial parts (e.g., relative height and shoot dry weight) and the RRW have also been evaluated as indicators of Al toxicity (Yan et al., 2009). In the present study, we used RRW, RSW, and RTW to comprehensively evaluate Al resistance in the 46 zoysiagrass accessions. Because changes in a single feature in response to Al stress may not be consistent for the same plant material, determining resistance based on only one feature is not reliable. Subordinate function analysis method based on multi-index measurement provides a way of comprehensive evaluation of material properties, and can overcome the shortage of only a few indicators to evaluate and make the result more objective and accurate. In the present study, the subordinate function values were calculated based on RRW, RSW, and RTW values; the greater the average subordinate function values, the stronger the resistance to Al. So there were 12 accessions $(26.09 \%)$ that belong to $\mathrm{Al}$ resistant with $\mathrm{F}$ values ranging from 0.5040 to $0.9726,9$ accessions $(19.57 \%)$ that belong to neutral resistance with $\mathrm{F}$ values ranging from 0.3572 to 0.4933 , and $25(54.34 \%)$ accessions that belong to $\mathrm{Al}$ sensitive with $F$ values ranging from 0.0016 to 0.3465 . In previous research, the average subordinate function values $(F)$ for seedling height, leaf age, root dry weight, and shoot dry weight were used to evaluate the $\mathrm{Al}$ resistance in 51 soybean accessions from Huang-Huai-Hai and the middle and lower reaches of the Yangtze River (Liu and Gai, 2004).

In plants, $\mathrm{Al}$ is absorbed mainly by roots and accumulates more in the root tip than in mature regions. Although high Al concentrations are toxic in plants, it has also been reported that in the annual grass Lolium multiflorum varieties Marshall and Gulf grown in nutrient solutions, the growth of root and shoot were promoted by Al at concentrations lower than $74 \mu \mathrm{M}$ (Rengel and Robinson, 1989). Promoted growth in the shoot and root were also observed in Poa pratensis when $\mathrm{Al}$ concentrations in the nutrient solution were lower than $320 \mu \mathrm{M}$ (Liu et al., 1995). In our present study, relative root growth was promoted by treatment of $1500 \mu \mathrm{M} \mathrm{Al}$ in most of the zoysiagrass accessions (Table 1), indicating greater Al resistance in zoysiagrass than the abovementioned grass species. 
In this study, we evaluated the $\mathrm{Al}$ resistance of 46 zoysiagrass accessions using small-scale liquid culture. Based on the results of the cluster analysis and ranking, the $\mathrm{Al}$ resistance of these accessions from China ranged from virtually none to very high. This indicates the diversity of zoysiagrass in China and its potential for horticultural breeding and development. Zoysiagrass accessions with high Al resistance were screened. These provide materials for further investigation on $\mathrm{Al}$ toxicity in zoysiagrass, and bioremediation of Al-rich acid soil in southern China.

\section{Literature Cited}

Armiger, W.H., C.D. Foy, A.L. Fleming, and B.E. Caldwell. 1968. Differential tolerance of soybean varieties to an acid soil high in exchangeable aluminum. Agron. J. 60:67-70.

Arroyave, C., R. Tolrá, T. Thuy, J. Barceló, and C. Pocherieder. 2013. Differential aluminum resistance in Brachiaria species. Environ. Exp. Bot. 89:11-18.

Baldwin, C.M., H. Liu, L.B. Mccarty, W.B. Bauerle, and J.E. Toler. 2005. Aluminum tolerance of ten warm-season turfgrasses. Intl. Turfgrass Soc. Res. J. 10:811-817.

Campbell, T.A., P.R. Jackson, and Z.L. Xia. 1994. Effects of aluminum stress on alfalfa root proteins. J. Plant Nutr. 17:461-471.

Chen, Z.C., N. Yamaji, R. Motoyama, Y. Nagamura, and J.F. Ma. 2012. Up-regulation of a magnesium transporter gene $O S M G T 1$ is required for conferring aluminum tolerance in rice. Plant Physiol. 159:1624-1633.

Delhaize, E., P.R. Ryan, and P.J. Randall. 1993. Aluminum tolerance in wheat (Triticum aestivum L.). II. Aluminum stimulated excretion of malic acid from root apices. Plant Physiol. 103:695702.

Duncan, R.R. and L.M. Shuman. 1993. Acid soil stress response of zoysiagrass. Intl. Turfgrass Soc. Res. J. 7:805-811.

Ezaki, B., K. Jayaram, A. Higashi, and K. Takahashi. 2013. A combination of five mechanisms confers a high tolerance for aluminum to a wild species of Poaceae, Andropogon virginicus L. Environ. Exp. Bot. 93:35-44.
Garcia-Oliveira, A.L., C. Benito, P. Prieto, R. de Andrade Menezes, C. Rodrigues-Pousada, $\mathrm{H}$. Guedes-Pinto, and P. Martins-Lopes. 2013. Molecular characterization of TaSTOPI homoeologues and their response to aluminum and proton $\mathrm{H}^{+}$toxicity in bread wheat (Triticum aestivum $\mathrm{L}$.). BMC Plant Biol. 13:134.

Garzón, T., B. Gunsé, A.R. Moreno, A.D. Tomos, J. Barceló, and C. Poschenrieder. 2011. Aluminum-induced alteration of ion homeostasis in root tip vacuoles of two maize varieties differing in Al tolerance. Plant Sci. 180:709715.

Gould, B., S. Mccouch, and M. Geber. 2014. Variation in soil aluminium tolerance genes is associated with local adaptation to soils at the Park Grass Experiment. Mol. Ecol. 23:60586072.

Guo, H., W. Ding, J. Chen, X. Chen, Y. Zheng, Z. Wang, and J. Liu. 2014. Genetic linkage map construction and QTL mapping of salt tolerance traits in zoysiagrass (Zoysia japonica). PLoS One 9:e107249.

Guo, H.L., J.P. Xuan, J.X. Liu, Y.M. Zhang, and Y.Q. Zheng. 2012. Association of molecular markers with cold tolerance and green period in zoysiagrass (Zoysia Willd.). Breed. Sci. 62:320-327.

Jan, F. 1991. Aluminum effects on growth, nutrient net uptake and transport in 3 rice (Oriza sativa L.) cultivars with different sensitivity to aluminum. Physiol. Plant. 83:441-448.

Keltjens, W.G. 1995. Magnesium uptake by Alstressed maize plants with special emphasis on cation interactions at root exchange sites. Plant Soil 171:141-146.

Kochian, L.V., M.A. Piñeros, and O.A. Hoekenga. 2005. The physiology, genetics and molecular biology of plant aluminum resistance and toxicity. Plant Soil 274:175-195.

Liu, H. 2005. Aluminum resistance among seeded bermudagrasses. HortScience 40:221223.

Liu, H., J.R. Heckman, and J.A. Murphy. 1995. Screening kentucky bluegrass for aluminum tolerance. J. Plant Nutr. 18:1797-1814.

Liu, Y. and J.Y. Gai. 2004. Identification of tolerance to aluminum toxin and inheritance of related root traits in soybeans (Glycine max (L.) Merr.). Soybean Science 23:164-168.
Maron, L.G., C.T. Guimarães, M. Kirst, P.S. Albert, J.A. Birchler, P.J. Bradburya, E.S. Buckler, A.E. Coluccio, T.V. Danilova, D. Kudrna, J.V. Magalhaes, M.V. Piñeros, M.C. Schatz, R.A. Wing, and L.V. Kochian. 2013. Aluminum tolerance in maize is associated with higher MATE1 gene copy number. Proc. Natl. Acad. Sci. USA 110:5241-5246.

Marschner, H. 1991. Mechanisms of adaptations of plants to acid soils. Plant Soil 134:1-20.

Murray, J.J. and C.D. Foy. 1978. Differential tolerance of turfgrass cultivars to an acid soil high in exchangeable aluminum. Agron. J. 70: 769-774.

Raman, H., B. Stodart, P.R. Ryan, E. Delhaize, L. Emebiri, R. Raman, N. Coombes, and A. Milgate. 2010. Genome-wide association analyses of common wheat (Triticum aestivum L.) germplasm identifies multiple loci for aluminum resistance. Genome 53:957-966.

Rengel, Z. and D.L. Robinson. 1989. Aluminum effects on growth and macronutrient uptake by annual ryegrass. Agron. J. 81:208-215.

Sivaguru, M., J. Liu, and L.V. Kochian. 2013. Targeted expression of SBMATE in the root distal transition zone is responsible for sorghum aluminum resistance. Plant J. 76:297307.

Tsutsui, T., N. Yamaji, C.F. Huang, R. Motoyama, Y. Nagamura, and J.F. Ma. 2012. Comparative genome-wide transcriptional analysis of $\mathrm{Al}$ responsive genes reveals novel Al tolerance mechanisms in rice. PLoS One 7:e48197.

Wang, Z., R. Ma, Y.J. Ma, and Y. Li. 2013. The drought resistance of 5 species of Lespedeza. J. Arid Land Res. Environ. 27(9):119-123.

Yan, J., J. Chen, T. Zhang, J. Liu, and H. Liu. 2009. Evaluation of aluminum tolerance and nutrient uptake of 50 centipedegrass accessions and cultivars. HortScience 44:857-861.

Ying, X.F., P. Liu, and G.D. Xu. 2006. Effect of aluminum on the isozymes of the seedlings of two soybeans [Glycine $\max$ (L.) Merri II] varieties. Plant Soil Environ. 52:262-270.

Zhou, G., E. Delhaize, M. Zhou, and P.R. Ryan. 2013. The barley MATE gene, HvAACT1, increases citrate efflux and $\mathrm{Al}^{3+}$ tolerance when expressed in wheat and barley. Ann. Bot. (Lond.) 112:603-612. 